\title{
Determining Critical Success Factors for Quality and Accreditation through Delphi Technique
}

\author{
Mohammed Ilyas ${ }^{1}$ \\ ${ }^{1}$ College of Science and Humanities, Prince Sattam bin Abdulaziz University, Saudi Arabia \\ Correspondence: Mohammed Ilyas, College of Science and Humanities, Prince Sattam bin Abdulaziz University, \\ Saudi Arabia. E-mail: m.ebrahim@psau.edu.sa
}

Received: April 4, 2018

Accepted: May 28, 2019

Online Published: May 31, 2019

doi:10.5430/ijhe.v8n3p148

URL: https://doi.org/10.5430/ijhe.v8n3p148

\begin{abstract}
This is an exploratory study which inquires and investigates the difficulties associated with Quality Assurance (QA) and Program Accreditation. The study highlights specific issues faced in the adoption and implementation of QA standards, sub standards and criteria. It identifies a few critical success factors (CSFs) and indigenised QA tools for program accreditation in Saudi Universities. The CSFs include Stakeholders' involvement, Top management support, orientation of staff with QA processes and standards, defining administrative procedures of accreditation, continuous quality improvement and assimilation of QA processes in day-to-day environment. Concurring with the Saudi Vision 2030 and National Transformation Program 2020, this study took the empirical approach and collected data from documentations and guidelines related to the National mission of QA and Accreditation initiated by agencies like National Centre for Academic Assessment and Accreditation (NCAAA) and Saudi Arabia Quality Framework (SAQF). This study suggests using the Delphi technique to evaluate the current scenario and ensure predictability judgments for a successful implementation of CSFs and best practices. As a group communication technique, the Delphi technique ideally suited this study making use of a group of individuals (e.g Faculty, Assessors) engaging themselves in resolving complex issues through a consensus. The Delphi technique is also indispensably relevant where no historical data exist, as many programs in Saudi universities are still not accredited. Finally, the Delphi Technique is also a method that helps identify risks, reduce bias in the data and estimate the outcome of events, truly representing predictability and versatility. The implications of this study include offering guidelines to programs and institutions undergo an accreditation process, by identifying true CSF and best practices.
\end{abstract}

Keywords: quality assurance, accreditation, Delphi technique, critical success factors, Saudi Arabia

\section{Introduction}

The outcome based learning and an emphasis on standards and criteria set down by accreditation agencies has not only made educational institutions more learning and knowledge oriented but has also changed their focus from a product-oriented to a more process and results-oriented education system. This can also be viewed as understanding of responsibilities by universities towards community and stakeholders, to provide quality education equipped with required market needs of knowledge, skills and competences. Educational institutions are often found employing Quality Assurance agencies all over the world to conduct accreditation, assessment and audit activities. These agencies use a number of instruments and tools, methods and practices, to prepare educational institutions for accreditation.

Knowledge and research about Quality Assurance have evolved considerably over time. Training of evaluators and assessors has become a common practice, and Quality Assurance agencies have been not only accumulating knowledge but are actively sharing their expertise internationally. Stensaker $(2007 ; 2008)$ argues that the era of "enthusiasm" is replaced by the era of "realism" in higher education with the introduction of Quality Assurance systems. Westerheijden et al (2007) state that the field of Quality Assurance is professionalizing and creating a positive effect on higher education and not only requires technical expertise of experts but also hard evidence of best work practices. Last, but not the least, a paradigm shift is seen in educational institutions where Quality Assurance is more directed towards getting accreditation and treated as a strategic objective (Beerkens,2018).

In the Saudi context, particularly due to the rapid increase in the number of universities during last one decade and in order to remain competitive, every post-secondary higher education institution has established an internal Quality 
Assurance system. The primary objective of this QA system is to create an environment conducive to quality assurance, continuous improvement and adopt such methods and practices that help to overcome challenges and obstacles to quality. The key responsibility of a QA unit in any teaching department is to liaison with the whole of academic community, including teachers, staff and students to put quality standards into practice and implement it at institutional as well as program levels. The Saudi Vision 2030 statement has also set such goals for all higher educational institutions to build "higher quality, multi-faceted Education" (Saudi Vision 2030, p 36), to design and construct "quality education systems" and an internal culture of quality that could help them achieve mission and goals, get recognition at national and international levels, and grow into a knowledge-based economy.

The National Transformation Program 2020, which was developed to help accomplish Saudi Vision 2030 and to establish strategic objectives and identify "initiatives" to achieve its targets, emphasizes on taking initiatives to "increase the capacity and quality of education" (NTP 2020, p.89) and "to achieve a prosperous future and sustainable development" (p.6). Al Ohali and Burdon (2013) emphasizes that Saudi strategy for higher education should be built around short and long term "tracks" out of which one of the tracks identified was quality assurance and granting accreditation to all educational institutions and universities in Saudi Arabia. Hence, this study aimed at identifying a few critical success factors (CSFs) and indigenised QA tools that are indispensable for achieving program accreditation in Saudi Universities.

The study began with identification of the problem, collected data from documentations and guidelines related to the National mission of QA and Accreditation initiated by agencies like National Centre for Academic Assessment and Accreditation (NCAAA) and Saudi Arabia Quality Framework (SAQF). The method of research was descriptive, empirical and qualitative. In addition to document analysis -NCAAA guidebooks and SAQF guidelines brainstorming interactions with the Faculty were also used as research instruments.

Since this study takes concurrence of the Saudi Vision 2030 and National Transformation Plan 2020, it is expected to act as a term of reference for education planners in Quality and Development Deanships at Saudi Universities. Both the Deanship and the Program Management can use these CSFs as a model to accelerate their accreditation plans. This study suggests using the Delphi technique to ensure predictability judgments and a successful implementation of CSFs suggested in this study. As a group communication technique, the Delphi technique ideally suited this study making use of a group of individuals (e.g Faculty, Assessors) who engaged themselves in resolving complex issues through a consensus.

This study will be complementing the research conducted by numerous experts and academicians (Víctor Reyes-Alcázar et al, 2012; Narasimha, 2013; Putri, and Yusof, 2009; Jehangiri, 2017; Karuppusami and Gandhinathan, 2006; Yusof \& Aspinwall, 2000; Nicholas, 2014; Mustafa et al, 2005; Lam et al 2011; Nutcache,2018; Yulisutiany, 2018; Zhang, 2018; Zheng, 2018) who however did not focus on CSFs for an effective Quality Management System and accomplishment of accreditation of universities. These studies mainly dealt with CSFs for accomplishing quality in fields like telecommunication, environmental sustainability, healthcare, manufacturing industries, marketing organizations, enterprise resources, and like. Hence, this research is a first study to discuss CSFs in an accreditation framework demonstrating a complete technique to implement the accreditation plan in accordance with the guidelines provided by NCAAA and SAQF.

To facilitate this research a framework was constructed comprising a few CSFs and QA tools that originated from NCAAA learning domains and SAQF level descriptors. The QA tools devised in this study adopted the Delphi technique which had assisted in the accreditation process and document management and portfolio management activities. It is also hoped that these tools will promote interpersonal collaboration, coordination, decision making, and bring automation in the Quality assurance planning and implementation. When Quality assurance activities are automated and regulated as a system, it saves time and effort of program accreditation teams.

The remaining part of this paper comprise Literature Review in section two, Problem statement in Section three, Research framework and Methodology in Section four, followed by Results and Discussion in Sections five and six respectively. In the end, there is a conclusion highlighting a few recommendations and future research potentials.

\section{Literature Review}

\subsection{Critical Success Factors}

Critical Success Factors (CSFs) are indicators that act as enablers to achieve an objective in a project or mission (Janse, 2019), to reach strategic goals within the mission and gain a competitive advantage (Hong, \& Kim, 2002). CSFs vary in each organization and are different for current and future objectives (Rockart, 1979). They are often created for a specific act, purpose, place, individuals, for a single department or, for the organization as a whole, but 
remain directly linked with the company's strategies (Leidecker, \& Bruno, 1984). The concept of CSF was first developed in McKinsey \& Co, in1961 and later popularized by Rockart (1979) who redefined them as criteria critical to success or failure of organizational goals and objectives. Gradually, CSFs came to be regarded essential for planning of strategies.

Not every company or business organization has the same CSFs as these factors depend upon demographics, specific characteristics, nature of competences required, marketing trends and like (Narasimha, 2013; Putri and Yusof, 2009; Jehangiri, 2017; Karuppusami and Gandhinathan 2006; Nicholas, 2014; Lam et al, 2011). Rockart (1979) considers the following six important sources of CSFs: teamwork, job security (or employment continuity), training and development, top management (leadership) support, customer satisfaction and continuous Improvement. Nutcache (2018) reiterates these sources and highlights how a project manager demands commitment from team members, retains them, offers them training to develop new skills, takes the support of the top management for all innovative projects, and works toward satisfaction of all stakeholders. All of these resources are linked together into a chain and viewed as best practices.

Several studies have accepted these six sources as implementation criteria for Total Quality Management (TQM) and have arranged them in the order of criticality (Talib et al, 2010, 2011; Salaheldin et al, 2015; Putri and Yusof, 2009; Coronado \& Antony,2002; Nicholas, 2014; Jehangiri, 2017). Talib et al. (2010), for instance, listed top-management commitment as the top critical success factor followed by customer focus and satisfaction. Other studies valued 'Conducting training' or 'continuous improvement' or 'stakeholder focus' as top of all critical success factors. Whatever is the order of criticality, these studies have one thing in common that these CSFs are critical ingredients to success of any organization and if objectives associated with the factors are not achieved, or strategies are not fulfilled, organization will fail.

In the Saudi context, a study of QA practices in Prince Sultan University (Albaqami, 2015), revealed top management commitment and leadership support as most critical in implementing Quality Assurance. Albaqami(2015) also found employees/faculty much aware and oriented towards QA but lack of motivation and resistance to its implementation were perceived as inhibitive factors to QA. The finding of this research also revealed lack of training and low morale due to their qualification an inhibiting factor in the implementation of Quality Assurance programs. Alharbi (2016), in another study, identified low research productivity, lack of interest in accreditation and lack of continuous improvement as challenges to higher education in Saudi Arabia. The study emphasized upon a need to adopt a benchmark strategy to resolve these challenges and felt the leadership of the university to monitor all sorts of quality outcomes. Almusallam (2013), however, held a different opinion and regarded learning outcomes and skills development as important CSFs in Saudi universities. The study insisted to shift the focus from rote learning to creative thinking and problem solving methods of teaching. The study also recognized the leadership responsibility for continuous improvement to achieve the goals of the university.

\subsection{Regulatory Frameworks in Saudi Arabia}

In the Arab region most Quality Frameworks have been developed in accordance with the Bologna agreement and under the guidelines of most European countries; however, there are proposals to develop an indigenized and standardized quality framework to use within the Arab region (Albaqami, 2015). For instance, Saudi Arabia replaced National Qualifications Framework (NQF) to Saudi Arabia Qualifications Framework (SAQF) with the objective to design a more indigenized framework to meet local and national needs of the kingdom. SAQF has made a rapid progress to develop itself as a unified system to enhance the quality of national qualifications network. Responding to the growing demand of quality and effectiveness in education, SAQF has worked indigenously and classified qualifications based on learning outcomes for both national and international accreditations. It has set certain standards and procedures for all national programs with a view to integrate education, training and employment in a single structure through principles of outcome based assessment. Besides setting qualifications standards, it has also set goals to create opportunities of socio-economic growth by identifying employability skills needed for the Saudi labor market. For this purpose, it aims at involving all stakeholders for a collective benefit (Almusallam, 2013; Alharbi,2016, Mustafa et al, 2005).

The competent governing body behind SAQF is the Education Evaluation Commission (EEC) which in order to materialize the SAQF plans and strategies established National Commission for Academic Accreditation and Assessment (NCAAA). It is now working as an independent legal entity with full administrative powers to assess and accredit academic and training institutions and their programs. NCAAA has established standards and processes for QA and Accreditation (NCAAA Handbook 1,2 and 3,2015) which can be seen as critical success factors required for accreditation. For instance, NCAAA regards Learning Outcomes as Quality Indicators or success factors 
for a program/ institution in Saudi Arabia. The achievement of these Learning outcomes depends upon teaching strategies, program evaluation mechanisms and student assessment practices for each learning domain.

\subsection{Delphi Technique}

Habibi, Sarafrazi and Izadyar (2014) consider Delphi technique as a structured, knowledge acquisition and data or evidence gathering technique, used for qualitative research to help group of experts reach a consensus on a subject in a decision-making process involving successive rounds and series of questions and discussions. Cyphert and Gant (1970) were the first to use the Delphi Technique at Ohio State University to develop faculty evaluation criteria. Since then several studies have investigated the use of Delphi technique in educational settings. Judd (1972) and Green (2014), for instance, recommend the use of Delphi technique to form guidelines, standards, and in predicting trends to accomplish university goals and objectives; Lewis (1984) suggests to use this technique to solve higher education problems; Scheele (1975) has emphasized upon involving stakeholders in a Delphi study, and so on.

In a qualitative framework, particularly in educational setting, the Delphi technique is useful if teamwork and interpersonal coordination is used to reduce bias in the data and to keep any one individual from making an undue influence on the outcome (Hsu, \& Sandford 2007). While In quantitative terms, this technique can also be used to identify risks on profitability and performance of products and services commercially. Turoff and Hiltz (1996) and Yousef, (2007) describe it as a method for predicting future through group consensus and group judgment supported by statistical reports and forecasts.

While applying this technique in a qualitative framework such as making an accreditation plan of university programs, this technique first requires the selection of a suitable facilitator with relevant knowledge and expertise, who can define the problem well. The facilitator then identifies small teams and groups with relevant experience and initiates a forecasting process, predicting the outcome of the efforts made by all teams. These teams are then required to participate in multiple rounds of discussions and focused talks acting as a 'think tank' or a panel of experts. The Delphi Technique typically requires two or three rounds of discussions where participants answer questions with justification, along with the provision of review and revision between rounds. Each team provides its independent estimates and predictions to the facilitator who reviews the data and prepares a feasibility report. During this process, the facilitator is monitoring by actual participation or collecting feedback of each team. Based on the participants' views, the facilitator thus identifies critical factors or criteria required for the effective implementation of Quality Assurance strategies. Delphi technique is popular for its versatility as it applicable in a wide range of environments, e.g., government schemes, business and industry forecasts, educational planning and forecasts, feasibility studies and so on.

\section{Problem Statement}

Universities and educational institutions face a great resistance from their faculty and staff for executing and implementing quality assurance program at the program level. At very few places, self-evaluation scales are measured in terms of the accreditation standards to prepare self-study reports (SSR) and Annual Program Reports (APR). Program specifications are not adhered at all; course specifications and course reports often do not match; there are deviations, non-conformances and non-compliances of the Quality and accreditation norms in templates; feedbacks and surveys of graduates, alumni and employers are not conducted on regular basis which makes it difficult to analyze the trends; program assessment by stakeholders is also not practiced, and so on. There are many such units and branches in remote areas where a Quality assurance program does not exist at all nor any program portfolios or documentations are maintained.

In such a scenario, it is important to explore such critical success factors and QA tools that would automate the Quality assurance activities and enable programs to claim eligibility for accreditation. In a business or industrial scenario, a quality assurance program when automated ensures quality control of all activities such as testing, risk assessment, turnover time, and any other component of quality which contributes to the validity of products and services. These organizations run such quality assurance program to provide Quality assurance tools to units and departments and facilitate automation of their quality related activities. Such Quality assurance tools are indigenized, centralized and often customized to streamline the company's operations. When applied in the context of educational institutions, such Quality Assurance program, can be designed to grant automation to all quality related activities and facilitate Quality Control regardless of whether the educational institution is aiming to acquire ISO certifications or national or international accreditation. This study aims to create an action plan or a blue print by identifying CSFs applicable to all types of certification and accreditation requirements. 


\section{Research Framework and Methodology}

A qualitative methodology was carried out, organizing the work in three steps: Informative Presentations through orientation workshop and training sessions; making of an Action Plan or an Implementation Manual; Actual Implementation. In the first step, informative sessions were conducted by experts on topics related to accreditation standards and other key areas such as Key Performance Indicators (KPIs), Program Learning Outcomes (PLOs) and Self Evaluation scales. Eventually, the presenters of these sessions formed teams or action groups to work on their respective areas of expertise. In the second step, an implementation manual was designed by accumulating the prerequisites from different accreditation templates. This manual also worked as a 'Term of Reference' to guide all teams or action groups working on accreditation tasks. Finally, in the actual implementation phase, these teams were involved in self-evaluation, probing into all the required templates and suggesting evidences to fulfill the accreditation requirements. Besides these three steps, opinions of key informants including Faculty, Staff and members of top management were also gathered to determine the exact state of Quality Assurance activities at each program level. The sample comprised 30 informants chosen through stratified sampling methods, out of whom 12 informants held key positions of QA coordinators of five different programs and 18 informants were the Faculty members of one of the programs offered in one of the departments of a Saudi university.

\section{Results}

The results of this study can be presented in three levels: first, the opinions and feedback of the key informants taken during formal and informal focus group discussions; second, the documentation highlighting significant excerpts from NCAAA handbooks and SAQF guidelines, in the Saudi context; finally, results obtained from the application of the Delphi technique on the sample of this study.

The opinion of key informants were both alarming and challenging. It revealed upon the researcher the big challenge ahead in order to obtain accreditation. The comments showed their resistance to Quality Assurance activities were found mainly due to the lack of awareness about the Quality Management System in general and unaware about norms, standards and criteria of accreditation, in particular.

In relation to the lack of awareness about quality and accreditation norms, the informants commented:

"Quality Assurance deteriorates our focus and we are not able to concentrate on primary task of teaching, assessment and students' development.

"QA is basically an extracurricular activity and should be treated as external to curriculum."

"There is too much documentation and evaluation feedback...."

Another factor that was found in their statements was about failure in understanding the templates and the manner in which QA and accreditation activities should be performed :

"There is no single document or template that tells us what to do and how to do it."

"The regulatory accreditation agency (NCAAA here) keeps changing its templates and publish new versions."

When asked about their involvement and participation, they observed:

"Accreditation is achievable only through compliance and adherence to norms in true sense but unfortunately people's involvement and participation in a continuous effort is scarce."

The information retrieved from regulatory resources like handbooks and official websites of Education and Training Evaluation Commission (EEC) and NCAAA revealed several such factors that could be qualified critical to the success of any accreditation efforts by any institution. For instance, NCAAA expects top management and role of leadership in coordinating Quality Assessment and Development programs, NCAA Handbook 1 spells out the following factors for QA and Accreditation which may be considered as expectations and CSFs for the sake of the current study: Continuing Quality Improvement, supportive relationships among staff without fear or inhibitions, willingness to acknowledge areas that need improvement, evidence based and independently verified assessment, to encourage creativity and innovation, diversity and flexibility. It also states that stakeholders should have substantial participation in planning and review processes with feedback regularly obtained, analyzed, and responded to.

NCAAA also mandates "A program must show the evidence of having made use of sub committees/ multiple teams to collect comprehensive sets of data / evidence; developing a procedures manual describing processes for quality assurance; advising on operational procedures for the planning and implementation of quality processes; maintaining systematic collections of reports that will be required for analysis of trends." ( NCAAA Handbook 2, p. 8). This 
recognizes the CSFs like teamwork, joint and collective working, adoption of an administrative manual for procedural purposes. It also identifies 17 Key Performance Indicators (KPIs) at the program level which need to be periodically measured with new and additional indicators identified to ensure the quality of the program. A few CSFs listed by these KPIs deal with Students' Evaluation and Quality of learning experience, their performance in the professional and/or national examinations, their employability and enrolment in postgraduate programs, Employers' evaluation of graduates proficiency, etc. On the faculty side, the KPIs include Ratio of students to teaching staff, research publications of faculty members, citations rate in refereed journals per faculty member and stakeholders; satisfaction of beneficiaries with the learning resources. Adherence to these KPIs is considered a critical success factor in the journey towards accreditation.

The Saudi Qualification Framework (SQF) too specifies three learning domains that can be categorized as CSFs as these are emphasized comprehensively in various documents such as Program Specifications, Course Specifications, and Annual Program Reports. These learning domains are Knowledge, Skills and competence. Knowledge refers to concepts, facts, information, ideas, and theories; Skills refer to the ability to apply knowledge in a practical context; competencies refers to efficiency as seen in personal attributes, values, and ethical responsibility in applying knowledge and skills in different social and cultural situations.

Delphi technique was applied on eleven small groups called sub committees in the sample of the study. Each subcommittee was required to work as a panel of experts and to arrive at a consensus through a series of meetings and group discussions. Considering that the Delphi technique is helpful particularly in estimating and forecasting outcomes of projects or missions, an explorative experimentation model was devised in which the team leader of each group was provided a small set of information about each of the NCAAA standards and criteria and was asked to collect more information and build upon a portfolio comprising data specific to the standards and criteria assigned to teams. This was consistent with the Delphi technique which requires selecting a suitable facilitator or expert of relevant knowledge and making sure that the problem is defined well. The teams were then asked to involve in self-evaluation and a close examination of events and activities to identify performance indicators, or predictors of performance.

Table 1. Framework of Delphi technique applied.

\begin{tabular}{|c|c|c|c|c|}
\hline Areas & Resource & Method & Instrument & Result/ Outcome \\
\hline $\begin{array}{l}\text { Identification } \\
\text { standards /criteria }\end{array}$ & $\begin{array}{l}\text { Handbooks and } \\
\text { Guidelines }\end{array}$ & $\begin{array}{l}\text { Sorting common } \\
\text { requirements }\end{array}$ & $\begin{array}{l}\text { Templates } \\
\text { PowerPoint }\end{array}$ & $\begin{array}{l}\text { Targets set for } \\
\text { accreditation }\end{array}$ \\
\hline $\begin{array}{l}\text { Formation of teams } \\
\text { of experts }\end{array}$ & Ind Staff & $\begin{array}{l}\text { Coaching } \\
\text { Mentoring }\end{array}$ & $\begin{array}{l}\text { Formal/ } \\
\text { meetings }\end{array}$ & $\begin{array}{l}\text { Strong committed } \\
\text { teams/ groups }\end{array}$ \\
\hline $\begin{array}{l}\text { Allocation of } \\
\text { standards and criteria }\end{array}$ & $\begin{array}{l}\text { Previous } \\
\text { Knowledge and } \\
\text { relevant } \\
\text { experience }\end{array}$ & Public Presentation & \begin{tabular}{lr}
\multicolumn{2}{l}{ Self-evaluation and } \\
sorting & through \\
content & analysis \\
methods &
\end{tabular} & $\begin{array}{l}\text { All standards/ } \\
\text { criteria allotted }\end{array}$ \\
\hline $\begin{array}{l}\text { Identification of data, } \\
\text { information, } \\
\text { evidences }\end{array}$ & $\begin{array}{l}\text { Official } \\
\text { Documentation }\end{array}$ & $\begin{array}{lr}\text { Groups } & \text { dynamics, } \\
\text { teamwork } & \text { and } \\
\text { inter-team coordination }\end{array}$ & $\begin{array}{l}\text { Visits and meetings, } \\
\text { data mining }\end{array}$ & $\begin{array}{l}\text { Relevant data and } \\
\text { evidence found }\end{array}$ \\
\hline $\begin{array}{l}\text { Storage and retrieval } \\
\text { of data }\end{array}$ & $\begin{array}{l}\text { Official } \\
\text { Documentation }\end{array}$ & $\begin{array}{l}\text { Portfolios and data } \\
\text { management }\end{array}$ & $\operatorname{Ar}$ & $\begin{array}{l}\text { Ready to access } \\
\text { data }\end{array}$ \\
\hline
\end{tabular}

A show of teamwork and interpersonal and inter-team coordination was advised to them in order to reduce a potential bias in the data and evidences and to keep any one individual or single team from making an undue influence on the outcome. It took almost 4 months to complete the whole process but the results were very encouraging. Table 1 summarizes the framework of the application of the Delphi technique.

\section{Discussion}

Based on findings of the study a few CSFs were formulated namely leadership and top management, staff training, teamwork, autonomy and empowerment and Performance improvement.

Leadership and top management is undoubtedly essential to strategic quality management. Current studies such as Seyfried (2019) have demonstrated the importance of strategic leadership in facilitating Quality assurance activities for program accreditation. The significance of role by strategic leadership is also acknowledged in NCAAA 
documents (NCAAA, 2015, Handbook 1). The Saudi Vision 2030 also emphasizes upon "effective leadership" that determines the strength and consistency of performance in areas such as planning, management and coordination. Quality assurance is most often initiated from top to bottom, but its success mainly depends on the extent to which the top is able to influence the bottom. In other words, the top management or administrators need to motivate faculty and staff to involve and participate in QA related activities. Truly speaking, in the context of Higher education, leadership cannot be seen in isolation as it requires the support of staff deployed for teaching and administration, which works on "empowerment paradigm." In other words, the leadership, comprising Deans and Vice Deans should practice empowerment in their work environment. Taking the macro perspective of empowerment to staff at work place, it not only improves individual's performance in the work context but also motivates them to incorporate competencies, attitudinal changes, less resistance to innovative ideas,

Training of staff is another best practice which helps institutions to achieve their Quality and Development goals. Training of staff is a response to the competencies gap that is identified between the actual and the desired level of competencies. By launching appropriate training Programmes, institutions can reduce this gap. The Vision 2030 (p.83) also considers human capital as crucial to the success of any project and emphasizes upon their "nurturing" and preparing them for strategic activities. NCAAA insists for disseminating its standards and criteria through training thus expecting institutions to establish a professional development framework (NCAAA, 2015). It also expects each program or department to carry out a process of self-assessment and determine the competences levels of its faculty and staff in order to identify the gap. This should be followed by conduct of informative sessions allowing opportunities for interaction and brainstorming among the Faculty and staff. A few informants endorsed the idea to conduct of training programs on NCAAA standards (NCAAA, 2018), KPIs (NCAAA, 2019), Program learning outcomes and similar other topics.

A need for Teamwork is emphasized by NCAAA in formation of sub committees/ multiple teams to collect comprehensive sets of data / evidence for quality assurance prior to the submission of an application for accreditation. A team-centred approach is recommended in order to ensure an integrated and unbiased presentation of facts and evidences in Self Study reports,. An Assessor of these documents empirically validates their effectiveness provided it is the product of group dynamics and teamwork. There can be two benefits of teamwork in Quality management: first, collective benefits to the institution as it reduces time and cost of documentation of evidence, improves interpersonal communication and the synergy resolves the issues of resistance too; secondly, there are individual benefits like improved satisfaction due to work completion, sense of belonging, motivation and loyalty to the institution and above all increased decision-making ability. One of the informants shared their volunteering to formulate teams and sub committees to work for program accreditation expected next year. According to them, a working model or an action plan for accreditation must transcend the limits of personal egos, individual interests and faculty should take into account the common goals and try to achieve them through consensus and a collective effort.

Autonomy and empowerment is however one of the most difficult success factors to develop in practice because the Saudi universities follow a different culture, which clashes with the values, priorities and roles assigned to Quality professionals who are still following traditional working patterns, subjected to "bureaucratization" of processes and "mechanization" of tasks. Any institution can develop only if its individuals have the ability to take decisions on matters related to institutional brand building as well as Quality and Development. Decision making is developed through autonomy granted to them by the organization either through procedural and administrative agreements or through empowerments.

There is a need to provide a certain degree of autonomy and empowerment to faculty and staff so that they develop their ability to face everyday challenges and improve their personal performances without inhibitions and intimidations. The significance of autonomy and empowerment at the grass root levels have empirical benefits in the form of choosing their individual strategies to perform and also assessing their performance. Truly speaking, autonomy and empowerment requires "decentralization" of decision-making; delegating tasks and responsibilities to unit and committee heads, to individual staff members, which may have a more direct impact on managerial effectiveness of leadership which they may later find it difficult to rationalize or some of them may be reluctant to redirect their roles and allow autonomy or decentralization. It can be argued here that autonomy and empowerment facilitates administrative processes and supports the operational procedures of an educational institutions. Such competent professionals may be identified and allowed to participate in decision-making on Quality and Development activities. To facilitate them, new rules may be introduced which may enable them to mould themselves in professional and management roles 
Performance improvement through coaching and mentoring is another key enabler or a CSF in Quality Assurance and Accreditation related activities. Performance improvement refers to providing opportunities of improvement and enhancement knowledge and skills. The facilitator of QA unit will first identify such individuals that show more resistance as well as those risk areas that could retard the developing of a Quality culture and a quality conducive environment. Thus through risk analysis methods, the facilitator prioritizes a support mechanism and succeeds in breaking the resistance as well as eradicate all potential risks, leading to great improvement. This technique is often applied in evaluating Key Performance Areas (KPAs) and Key Result Areas (KRAs) of employees in a work scenario. Adopting these best practices in an educational setting undoubtedly initiates a process of continuous quality improvement.

Table 2 shows the current and desired situation of these factors as was evident from the sample of the study. Some of the desired situation was achieved by applying the Delphi technique which proves its relevance, transferability and validity in similar situations.

Table 2. CSFs in Current situation vs. desired situation

\begin{tabular}{|c|c|c|c|}
\hline Current situation & & Desired situation & \\
\hline $\begin{array}{l}\text { Leadership Top } \\
\text { down approach }\end{array}$ & $\begin{array}{l}\text { Only project related or occasional } \\
\text { flexibility is seen in leadership } \\
\text { behavior; fewer opportunities of } \\
\text { attendance in leadership development } \\
\text { programs by subordinates (Staff/ } \\
\text { Faculty). }\end{array}$ & $\begin{array}{l}\text { Leadership } \\
\text { Bottom up } \\
\text { approach }\end{array}$ & $\begin{array}{l}\text { A decentralization or delegation of } \\
\text { powers/ authority/ autonomy on } \\
\text { regular basis is needed. Subordinates } \\
\text { (faculty/ staff) should participate in } \\
\text { leadership development programs. } \\
\text { Industry and benchmark leadership } \\
\text { should be demonstrated }\end{array}$ \\
\hline Training of staff & $\begin{array}{l}\text { Training is offered in few areas only } \\
\text { and is for insufficient duration. It is } \\
\text { more challenging to accomplish the } \\
\text { organizational goals. Training is relied } \\
\text { upon external trainers. Significant } \\
\text { weaknesses or gaps are observed in } \\
\text { many areas. }\end{array}$ & Training of staff & $\begin{array}{l}\text { Need felt for skills up gradation of staff/ } \\
\text { employees. Opportunities to be given to } \\
\text { internal trainers. Skills gaps to be filled } \\
\text { up through need based training of staff. }\end{array}$ \\
\hline Teamwork & $\begin{array}{l}\text { Teams are formed as committees to } \\
\text { perform formal/periodical tasks and for } \\
\text { short durations. Teams lack rigor and } \\
\text { consistent performance. }\end{array}$ & Teamwork & $\begin{array}{l}\text { Alignment with organizational } \\
\text { strategies should be evident in teams; } \\
\text { teams should be responsive to } \\
\text { challenges and set performance } \\
\text { benchmarks. }\end{array}$ \\
\hline $\begin{array}{l}\text { Autonomy and } \\
\text { empowerment }\end{array}$ & $\begin{array}{l}\text { Systematic approach lacking in granting } \\
\text { autonomy to the subordinates. }\end{array}$ & $\begin{array}{l}\text { Autonomy and } \\
\text { empowerment }\end{array}$ & $\begin{array}{l}\text { Subordinates need to be integrated } \\
\text { with organizational functions and } \\
\text { activities through autonomy and } \\
\text { empowerment }\end{array}$ \\
\hline $\begin{array}{l}\text { Performance } \\
\text { improvement }\end{array}$ & $\begin{array}{l}\text { Improvement is achieved through } \\
\text { reacting to problems. Some adverse } \\
\text { trends evident in performance at both } \\
\text { individual and institutional levels. } \\
\text { Orientation towards performance is less } \\
\text { evident. }\end{array}$ & $\begin{array}{l}\text { Performance } \\
\text { improvement }\end{array}$ & $\begin{array}{l}\text { More proactive approach needed to } \\
\text { address issues Need to develop tools } \\
\text { for organizational learning for } \\
\text { improvement, refinement and } \\
\text { innovation backed by analysis of } \\
\text { organizational performance levels. }\end{array}$ \\
\hline
\end{tabular}

\section{Conclusion}

The Delphi technique is particularly relevant to establish causation where no historical data exist or where there is no precedence (Avella, 2016). This technique was uniquely ideal for the sample and the purpose of the current study as many programs in Saudi universities are still not accredited. The Delphi technique has been in practice with three versions : first, the "policy" Delphi when there is a need to devise a strategy to resolve a specific problem; second, the "classical" Delphi used to forecast a future event; finally, the "decision-making" Delphi for effective decision making (Linstone \& Turoff, 2002). 
For the current study and due to its objectives, the third version of "decision-making" Delphi was adopted. The multiple rounds of meetings and group discussions with the subcommittees and teams helped in decision making and arriving at a consensus. The researcher of the current study played the twin role of a "planner" and a "facilitator" but refrained from becoming an "instrument" or a "contributor" of this qualitative study to avoid and minimize the researcher bias. The research restricted his role to arranging panel discussions with the objective to identify and prioritize key facts and figures of Quality and Accreditation, focusing on NCAAA documents and their requirements. Using the Delphi technique as a strategy, the focus was on the delivery mechanism and the desired output. Eventually, each panel or subcommittee was meant to establish a list of facts and evidences.

The critical success factors (CSFs) identified in this study are a result of observation, study of documentation and lengthy, holistic discussion with panelists. It is highly recommended that the top management shows their commitment to these CSFs particularly employee training and empowerment, to act as benchmarks for other programs to emulate this success. Hence, it was necessary to link these CSFs with QA initiatives involving all individuals at all positions in order to accomplish accreditation. A great deal of lesson was also learnt during the course of this study which would greatly enhance the success of Quality initiatives. The administrators can use the findings of this study as a model to plan the self-evaluation processes required for quality accreditation. The benefits of this model would be the implementation of teamwork, coordination, decision making approach and reaching consensus to resolve issues, reduction in non-conformances and non-compliance, reduction in rework and repetition, and so on. Future research using the Delphi technique and CSFs can be carried out for institutional development requiring radical redesign of practices and taking initiatives to optimize the program learning outcomes, assessment strategies and making institutions more productive to social and community needs.

\section{References}

Abdullah, Riyaz Sheikh. (2017). Application of Saudi's National Qualifying Framework in System Analysis \& Design Course International Journal of Management Excellence, 10(1), December 2017. https://doi.org/10.17722/ijme.v10i1.384

Al Ohali, M., \& Burdon, S. (2013). International collaboration. In Smith, L. \& Abouammoh, A. (Eds.), (2013). Higher Education in Saudi Arabia: Achievements, Challenges and Opportunities (pp.159-166). The Netherlands: Springer. http://dx.doi.org/10.1007/978-94-007-6321-0_15

Albaqami, Saud. (2015). Implementing Quality Assurance in Saudi Arabia: A Comparison between the ESO and the MICRO Level at PSU. Higher Education Societies, 5(3), 66-81. https://doi.org/10.5539/hes.v5n3p66

Alharbi, Eman Abdulrahman Radi. (2016). Higher Education in Saudi Arabia: Challenges to Achieving World-Class Recognition. International Journal of Culture and History, 2(4), 169-172. https://doi.org/10.18178/ijch.2016.2.4.058

Almusallam, Abdullah. (2013). Accreditation and Quality Assurance in Post Secondary Education in the Kingdom of Saudi Arabia. Journal of Higher Education and Science, 3(3), 193-199

Avella, J. R. (2016). Delphi panels: Research design, procedures, advantages, and challenges. International Journal of Doctoral Studies, 11, 305-321. https://doi.org/10.28945/3561

Beerkens, Maarja. (2018). Evidence-based policy and higher education quality assurance: progress, pitfalls and promise. European Journal of Higher Education, 8(3), 272-287. https://doi.org/10.1080/21568235.2018.1475248

Coronado, RB, Antony, J. (2002). Critical success factors for the successful implementation of six sigma projects in organizations. The TQM Magazine, 92-99. https://doi.org/10.1108/09544780210416702

Cyphert, F., and Gant, W. (1970). The Delphi Technique: A tool for collecting opinions in teacher education. Journal of TeacherEducation, 21, 417-425. https://doi.org/10.1177/002248717002100316

EEC (2018). https://www.eec.gov.sa/nqf

Green, Ravonne A. (2014). The Delphi Technique in Educational Research. SAGE Open April-June 2014: 1-8.

Habibi, Arash, Sarafrazi, Azam \& Izadyar, Sedigheh. (2014). Delphi Technique Theoretical Framework in Qualitative Research. The International Journal Of Engineering And Science (IJES), 3(4), 8-13.

Hong, K. K., \& Kim, Y. G. (2002). The critical success factors for ERP implementation: an organizational fit perspective. Information \& Management, 40(1), 25-40. https://doi.org/10.1016/S0378-7206(01)00134-3 
Hsu, C., \& Sandford, B. (2007). The Delphi technique: Making sense of consensus. Practical Assessment, Research and Evaluation, 12, 1-8.

Janse, B. (2019). Critical Success Factors. Retrieved [on 23 April, 2019] from ToolsHero: https://www.toolshero.com/strategy/criticalsuccess-factors/

Jehangiri R. (2017). Identification of Critical Success Factors for Total Quality Management Implementation in Organizations. Int J Econ Manag Sci, 6(420). https://doi.org/10.4172/2162-6359.1000420

Judd, R. (1972). Forecasting to consensus gathering: Delphi grows up to college needs. College \& University Business, $53(1), 35-38,43$.

Karuppusami G, Gandhinathan R. (2006). Pareto analysis of critical success factors of total quality management. The TQM Magazine, 372-385. https://doi.org/10.1108/09544780610671048

Lam SY, Lee VH, Ooi KB, Lin B. (2011). The relationship between TQM, learning orientation and market performance in service organisations: an empirical analysis. Total Quality Management and Business Excellence, 1277-1297. https://doi.org/10.1080/14783363.2011.631337

Leidecker, J. K., \& Bruno, A. V. (1984). Identifying and using critical success factors. Long range planning, 17(1), 23-32. https://doi.org/10.1016/0024-6301(84)90163-8

Lewis, D. (1984). Characteristics of selected Delphi studies and their perceived impact in higher education (Doctoral dissertation University of Florida, Order No. DA842938). Ann Arbor, MI: University Microfilms International.

Linstone, H. A., \& Turoff, M. (Eds.). (2002). The Delphi method: Techniques and applications. Retrieved from http://is.njit.edu/pubs/delphibook/delphibook.pdf

Mustafa D., Nizamettin B., Selim Z., Mehres T. (2005). Critical Factors of Total Quality Management and its effect on performance in Healthcare Industry: A Turkish Experience. problems and perspectives in management, $4 / 2005$

Narasimha, 'Peri. (2013). Critical Success Factors For A Successful Test. Wipro Technologies.

National Transformation Program 2020, Government of Saudi Arabia.

NCAAA. (2015). Handbook for National Qualification Framework for Higher Education in the Kingdom of Saudi Arabia. National Commission for Academic Accreditation \& Assessment, Riyadh, Kingdom of Saudi Arabia.

NCAAA. (2015). Handbook for Quality Assurance and Accreditation in Saudi Arabia Part 1, 2 3: The System for Quality Assurance and Accreditation. National Commission for Academic Accreditation \& Assessment, Riyadh, Kingdom of Saudi Arabia

NCAAA. (2018). NCAAA Standards for Program accreditations. National Commission for Academic Accreditation \& Assessment, Riyadh, Kingdom of Saudi Arabia.

NCAAA. (2019). Handbook for NCAAA Key Performance Indicators. National Commission for Academic Accreditation \& Assessment, Riyadh, Kingdom of Saudi Arabia.

Nicholas, J. (2014) Hoshinkanri and Critical Success Factors in Quality Management And Lean Production. Total Quality Management \& Business Excellence, 27, 1-15. Quotd in Jehangiri R (2017) Identification of Critical Success Factors for Total Quality Management Implementation in Organizations. Int J Econ Manag Sci 6: 420.

Nutcache. (2018). How To Identify Critical Success Factors in a Project | Nutcache (https://www.nutcache.com/blog/how-to-identify-critical-success-factors-in-project-management/

Putri, Nilda Tri \& Yusof, S.M. (2009). Critical Success Factors for Implementing Quality Engineering Tools and Techniques in Malaysian's and Indonesian's Automotive Industries: An Exploratory Study Proceedings of the International Multi Conference of Engineers and Computer Scientists 2009 Vol II IMECS 2009, March 18 - 20, 2009, Hong Kong.

Rockart, J. F. (1979). Chief executives define their own data needs. Harvard business review, 57(2), 81-93.

Salaheldin Ismail, Salaheldin Samia, Fathi Mohammad, S. Shawaheen. (2015). Critical Success Factors For Total Quality Management Implementation in Jordanian Healthcare Sector. European Scientific Journal, 11(13). 
Salaheldin SI. (2009). Critical success factors for TQM implementation and their impact on performance of SMEs. International Journal of Productivity and Performance Management, 58, 215-237. https://doi.org/10.1108/17410400910938832

Saudi Vision 2030. Government of Saudi Arabia.

Scheele, D. (1975). Reality construction as a product of Delphi interaction. In H. A. Linstone \& M. Turoff (Eds.), The Delphi method: Techniques and applications. Boston, MA: Addison-Wesley.

Seyfried, Markus. (2019). Undisclosed desires: quality managers' normative notions regarding the implementation of quality management. Assessment \& Evaluation in Higher Education, 44(7), 1106-1119. https://doi.org/10.1080/02602938.2019.1573970

Stensaker, Bjørn. (2007). Impact of Quality Processes. In Embedding Quality Culture in Higher Education. A Selection of Papers from the 1st European Quality Assurance Forum, edited by Lucien Bollaert, Sanja Brus, Bruno Curvale, Lee Harvey, Emmi Helle, Henrik Toft Jensen, Janja Komljenovič, Orphanides, Andreas, and Andrée Sursock, 59-62. Brussels: European University Association.

Stensaker, Bjørn. (2008). Outcomes of Quality Assurance: A Discussion of Knowledge, Methodology and Validity. Quality in Higher Education, 14(1), 3-13. https://doi.org/10.1080/13538320802011532

Talib F., Rahman Z., Azam M. (2011). Best Practices of Total Quality Management Implementation in Health Care Settings. Health Marketing Quarterly. https://doi.org/10.1080/07359683.2011.595643

Talib, F., Zillur, R., Qureshi, M. (2010). Pareto analysis of Total Quality Management Factors Critical to success for service Industries. International Journal for Quality Research, UDK-005.6, Original Scientific paper (1.01), 4(2).

Turoff, M., \& Hiltz, S. (1996). Computer based Delphi processes. In M. Adler \& E. Ziglio (Eds.), Gazing into the oracle: The Delphi Technique and its application to social policy and public health. London, England: Kingsley

Víctor Reyes-Alcázar, Antonio Torres-Olivera, Diego Núñez-García \& Antonio Almuedo-Paz. (2012). Critical Success Factors for Quality Assurance in Healthcare Organizations, Quality Assurance and Management,Prof. Mehmet Savsar (Ed.), ISBN: 978-953-51-0378-3, InTech. https://doi.org/10.5772/33081

Westerheijden, Don F., Bjørn Stensaker, \& Maria João Rosa, eds. (2007). Quality Assurance in Higher Education: Trends in Regulation, Translation and Transformation Higher Education Dynamics. Dordrecht: Springer. https://doi.org/10.1007/978-1-4020-6012-0

Yousef, M. I. (2007). Using experts' opinions through Delphi technique, Practical Assessment Research \& Evaluation, 12(4). Retrieved from http://pareonline.net/getvn.asp?v=12\&n=4

Yulisutiany, I. (2018). Study of Education Competency and Effect on Learning Process of BCCT Method on Educational Group of Education Age (PAUD) in Sukasari Bandung. International Journal of Educational Technology and Learning, 3(2), 69-77. https://doi.org/10.20448/2003.32.69.77

Yusof, S. and Aspinwall, E. (2000). Critical success factors in small and medium enterprises: survey results. Total Quality Management, 11(4-6), 448-462. https://doi.org/10.1080/09544120050007760

Zhang, W. B. (2018). Endogenous Economic Growth with Education Subsidies. International Journal of Emerging Trends in Social Sciences, 2(1), 10-16. https://doi.org/10.20448/2001.21.10.16

Zheng, J. (2018). The Incorporation of Subject Knowledge in Teaching Scientific Translation. International Journal of English Language and Literature Studies, 7(2), 45-49. https://doi.org/10.18488/journal.23.2018.72.45.49 